\title{
The gambling take: balancing revenues and responsibilities
}

$\mathrm{P}$ eople who frequent casinos are likely familiar with an old gambling adage: you can't beat the house. There is, however, a way to profit handsomely from gambling without beating the house - by running the house.

Government-operated gaming accounts for the vast majority of Canadian gambling revenues: $90 \%$, according the Canadian Partnership for Responsible Gambling. Charities and horse racing account for the rest. In fiscal year 2006/07, gambling netted provincial governments $\$ 6.8$ billion, nearly $\$ 11$ million more than the year before. Without doubt, gambling is good for provincial budgets, but experts claim more research is needed to determine if the continued proliferation of gambling could prove damaging to public health.

Many gambling researchers claim there are advantages to having governments, rather than private companies, operate gaming venues but warn against overreliance. The growth of gambling in the country has, however, resulted in one unexpected benefit: Canada now leads the world in gambling research. But as it stands today, research into the public health implications of widespread gambling is still immature, though some experts say potential social costs include increases in addiction, depression, family neglect and social isolation.

Prohibited in most societies for much of human history, gambling is now considered a socially acceptable activity, though the public tends to favour tight regulation. But policies to regulate gambling have a way of becoming distorted when governments rely too heavily on craps and slots to pay bills.

"The challenges in Canada and places like Australia are that gambling has become a fairly important revenue source. In Australia, it's reached 15\% in some states," says William Eadington, an economics professor and direc- tor of the Institute for the Study of Gambling and Commercial Gaming at the University of Nevada, Reno. "In many cases it hasn't reached a threshold where removal would cause desperation. It might be uncomfortable but it wouldn't create a crisis. It's when you reach that latter stage when your options are really reduced."

At $\$ 1.8$ billion, Ontario's net gaming revenue in fiscal year 2006/07 was the highest of any province, though it comprised only $2 \%$ of total government revenues. Alberta, where 4.4\% (\$1.7 billion) of government revenues came from gambling, is the province most dependent on gaming, while Prince Edward Island, at $1.4 \%$ ( $\$ 16.9$ million), is the least. On average, the provinces garnered $2.4 \%$ of their revenues from slot machines, video lottery terminals, lotteries, bingos and casinos. The take

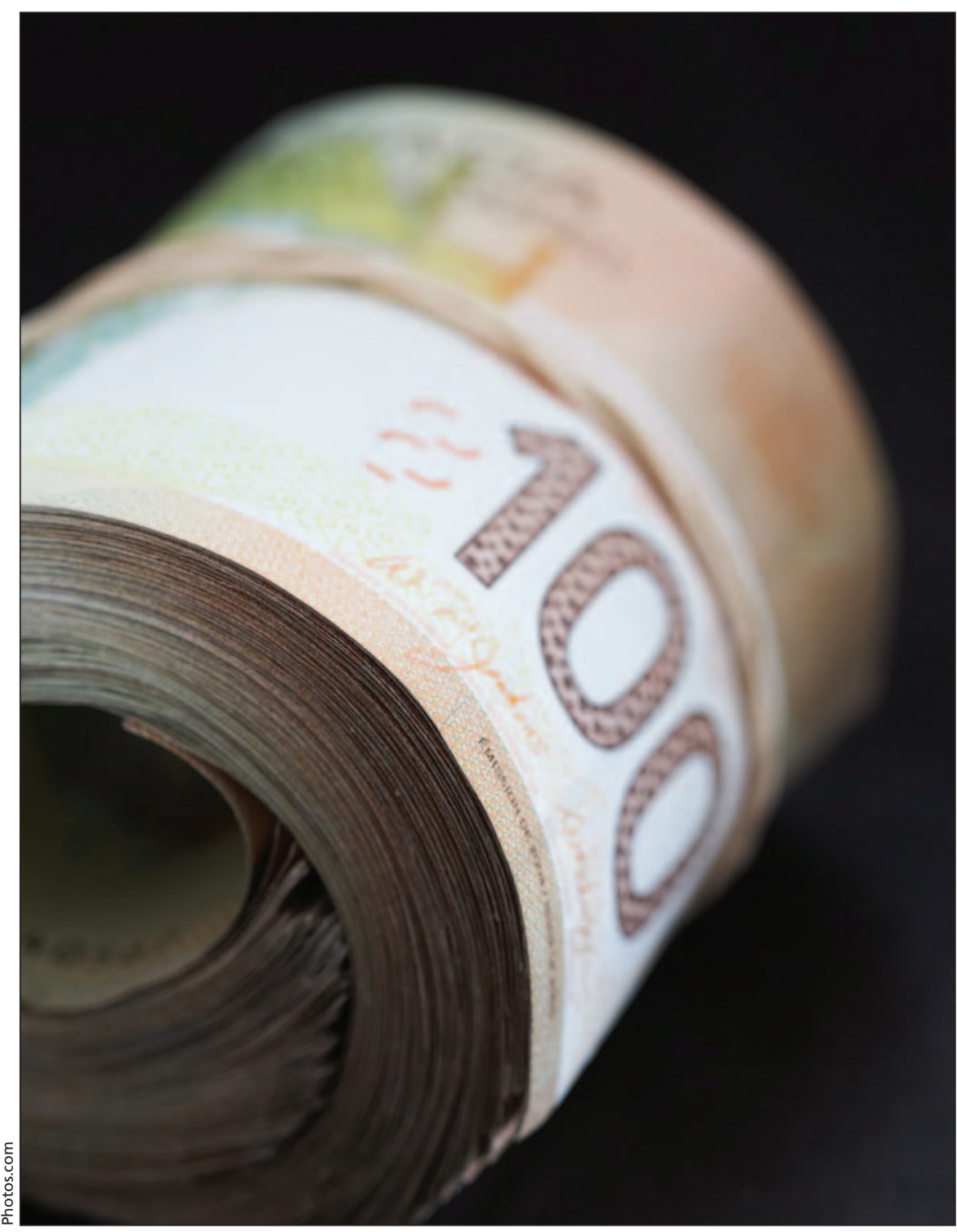

On average, provinces garner $2.4 \%$ of their revenues from slot machines, video lottery terminals, lotteries, bingos and casinos. 
doesn't include profits from Internet gambling, which, despite widespread belief to the contrary, is illegal in Canada.

Provincial gambling profits fund various services, many related to health care. For example, in fiscal year 2003/04, according to the Canada West Foundation, British Columbia contributed $\$ 147$ million of its gaming revenue to a "health special account." Alberta devoted \$209 million of its gambling earnings to health and wellness programs. Across the country, millions are earmarked for problem gambling research, treatment and awareness prevention, and to promote responsible gaming.

Because governments run gambling in Canada, more profits go toward services that benefit the public than into the pockets of business owners. But what are the dangers of the marriage between government and gambling? According to researchers, there are many.

"In Canada, the government is the primary benefactor of gambling profits, so there is a lot of political pressure to legitimize it or to divert criticism," says Eadington.

Governments may also find themselves in a strange relationship with problem gamblers, says Peter Collins, a professor of public policy studies and director of the Centre for the Study of Gambling at the University of Salford, in England. "It's quite difficult for governments, which are responsible for player protection but are also beneficiaries of player excesses."

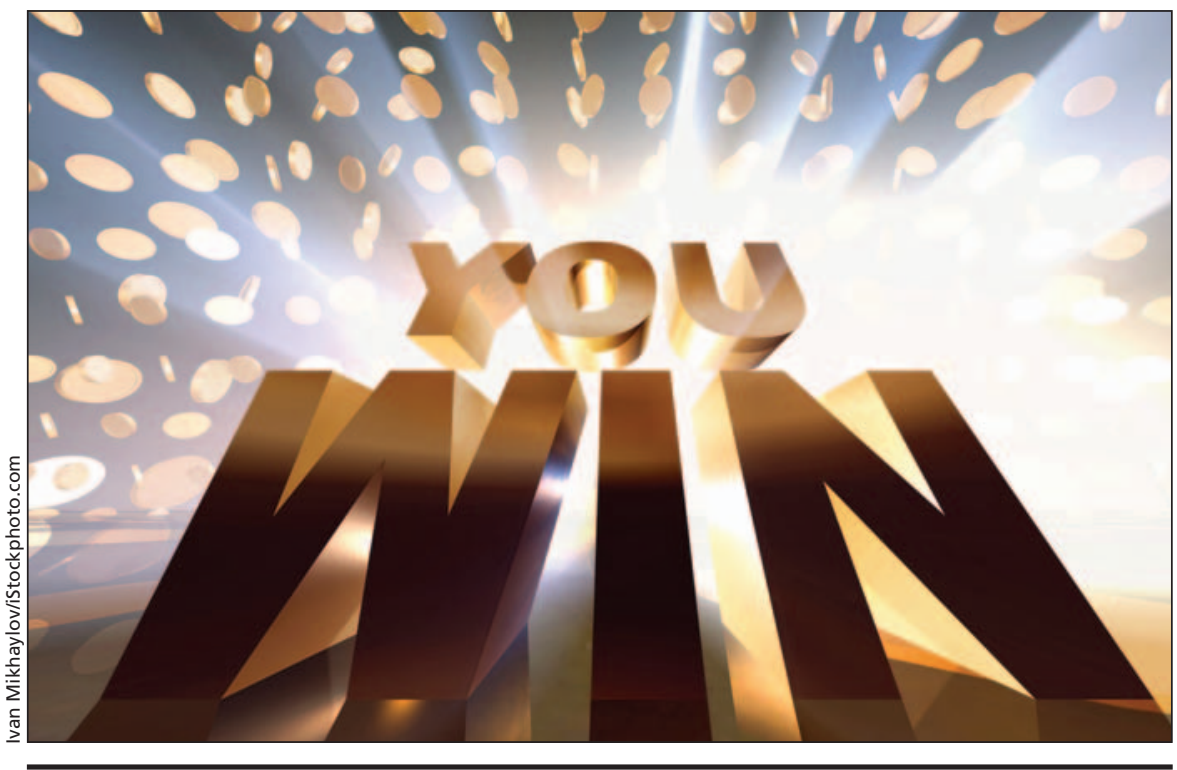

Governments are becoming addicted to gambling revenues and, thus, are the primary beneficiaries of player excesses but, simultaneously, are responsible for protecting players from social costs like addiction and depression.

ments operate gambling venues is improved political responsiveness because, unlike in private industry, where the top priority is pleasing shareholders, politicians are sensitive to public views. This sensitivity results in another benefit: more research money.

"Canada generates somewhere in the vicinity of $\$ 100$ million a year for research, treatment and education of problem gambling issues. A lot of this is a byproduct of the political sensitivities that gambling brings about," says Eadington.

Australia also makes significant contributions to gambling research, as does New Zealand. But in countries

\section{"Gambling has become a fairly important revenue source." - William Eadington}

Collins claims gaming-dependent governments could also run into financial problems in 2 situations. If public sentiment ever turned against gambling, they would have to find revenue elsewhere, which could result in the never-popular raising of taxes. People also gamble less during recessions, says Collins, which would mean less government income for essential services during already difficult periods.

An advantage of having govern- like the United States, where industry runs almost all forms of gaming outside of state lotteries, money for gambling research is hard to come by.

"We're light years behind Canada," says Lia Nower, director of the Center for Gambling Studies at Rutgers University, in New Jersey. "There's not a lot of research going on in the States regarding the public health implications of gambling because there isn't a government-sponsored funding mecha- nism. The gaming industry certainly isn't going to fund that research. The other problem is that these studies are extremely expensive because you have to prove a causal connection. Just because there is crime or bankruptcies doesn't necessarily mean gambling caused those problems. The studies have to be longitudinal, they have to have a large sample and they have to have a lot of economic measures."

There are currently 2 major socioeconomic gambling studies being conducted in Canada: one in Nova Scotia, the other in Belleville, Ontario. The Belleville study, led by Robert Williams of the University of Lethbridge, will be one of the most extensive ever conducted. Researchers will follow 4000 adults over a 5-year period before and after the opening of a casino.

"Until the mid-1990s, there was very little significant research on the social impacts of gambling," says Eadington. "The growing role of gambling in Canada has forced a lot more research, but we started with a base of substantial ignorance. Alcohol and tobacco have been studied for a generation and the amount of scientific work is richer. I think gambling research will get there but it's lagging by 20 years." — Roger Collier, CMAJ

DOI:10.1503/cmaj.080875 